\title{
Shock index utility to predict mortality in pediatric patients with septic shock or severe sepsis
}

\author{
Claudia S. López-Reyes ${ }^{1}$, Lilia N. Baca-Velázquez ${ }^{1}$, Miguel Á. Villasís-Keever ${ }^{2}$ and Jessie N. Zurita-Cruz ${ }^{3 *}$ \\ ${ }^{1}$ Unidad de Terapia Intensiva Pediátrica; ${ }^{2}$ Unidad de Investigación Médica en Epidemiología Clínica; ${ }^{3}$ Unidad de Investigación en Nutrición. Unidad \\ Médica de Alta Especialidad, Hospital de Pediatría Dr. Silvestre Frenk Freund, Centro Médico Nacional Siglo XXI, Ciudad de Mexico City, Mexico
}

\begin{abstract}
Background: Pediatric sepsis is considered the main cause of hospital death around the world. Many groups have tried to create tools that facilitate its early identification, as the shock index (SI), defined as the ratio between cardiac frequency and systolic blood pressure. The objective of this study was to determine the utility of SI to predict mortality in pediatric patients with severe sepsis and septic shock. Methods: A retrospective cohort study with 165 pediatric patients with severe sepsis or septic shock in the Pediatric Intensive Care Unit. SI was calculated at diagnosis and at 2, 4, and $6 \mathrm{~h}$ after (SI2, SI4, and S(6). We divided the population into two groups depending on their outcome: survivors and non-survivors. The statistical analysis was performed with Mann-Whitney U-test and Chi-squared tests. The risk factors were compared between the survivors and the dead, and we calculated the odds ratio (OR). Results: The median value of SI was compared between groups; in the group of septic shock, SI showed a tendency to remain high in SI4 and SI6 ( $p=0.010$ and $p=0.005$, respectively). Among the survivors and the non-survivors, we found that in the latter, SI was progressively increased in SI4 and SI6 ( $p$ < 0.05). High values of SI4 and SI6 increased the risk of death in patients (SI4: OR = 442.1 confidence interval [CI] $95 \%$ 54.2-3601.7, $p<0.001$ and SI6: OR = $81951.3 \mathrm{Cl} 95 \%$ 427.1-15700000, $p<0.001)$. Conclusions: High values of SI are associated with increased mortality. The IS6 value is the most useful to predict mortality.
\end{abstract}

Key words: Severe sepsis. Septic shock. Shock index.

\section{Utilidad del índice de choque para predecir la mortalidad en pacientes pediátricos con sepsis grave o choque séptico}

\section{Resumen}

Introducción: La sepsis en pediatría es la principal causa de muerte hospitalaria. Se han intentado crear herramientas que faciliten su identificación, como el índice de choque (IC7), definido como el cociente entre frecuencia cardíaca y tensión arterial sistólica. El objetivo de este trabajo fue identificar el mejor momento del IC para predecir la mortalidad en pacientes pediátricos con sepsis grave y choque séptico. Métodos: Cohorte retrospectiva con 165 pacientes pediátricos que desa-

Available online: 23-11-2018 Bol Med Hosp Infant Mex. 2018;75:192-198 
rrollaron sepsis grave y choque séptico en la Unidad de Terapia Intensiva Pediatrica. Se calculó el IC al diagnóstico (ICO), a las dos, cuatro y seis horas posteriores al mismo (IC2, IC4 e IC6). Se crearon dos grupos según el desenlace (sobrevivientes/muertos). La comparación estadística se realizó con prueba U-Mann Whitney y そ2. Se compararon los factores de riesgo entre los sobrevivientes y muertos, calculando la razón de momios (RM). Resultados: Se comparó el valor del IC entre grupos; en el grupo de choque séptico, el IC se encontró más elevado en IC4 e IC6 ( $p=0.010$ y $p=0.005)$. Se encontró que, en los pacientes muertos, el IC incrementó progresivamente su valor en IC4 e IC6 ( $p<0.05)$. Los valores de IC4 e IC6 elevados incrementaron el riesgo de muerte en los pacientes (IC4, RM: 442.1; intervalo de confianza al [IC] 95\%: 54.2-3,601.7; $p$ < 0.001; e IC6, RM: 81,951.3; IC 95\%: 427.1-15,700,000; $p$ < 0.001). Conclusiones: La elevación del valor del IC se asocia con mayor mortalidad de la sepsis. El valor de IC6 es el más útil para predecir mortalidad.

Palabras claves: Sepsis grave. Choque séptico. Índice de choque.

\section{Introduction}

Pediatric sepsis is an important health problem since it is considered the leading cause of hospital death worldwide. It has been reported that $8.2 \%$ of children admitted to Pediatric Intensive Care Units (PICU) have sepsis: $4 \%$ severe sepsis and $2 \%$ septic shock with a mortality rate of $25-48 \%$, depending on the patient comorbidities ${ }^{1-5}$. Sepsis is diagnosed according to clinical data, among which are heart rate (HR), temperature, and respiratory rate; however, these can be mixed with response to trauma, besides being data of an infectious process. Given this situation, multiple biochemical markers that aid in the identification of the presence, severity, and prognosis of sepsis have been studied ${ }^{6}$. The most commonly used marker in medical practice is serum lactate; however, in some medical units, it is not always available or is merely not assessed promptly because the clinical findings do not justify its systematic measurement, which delays the diagnosis and treatment of critical patients ${ }^{7}$.

There are numerous prognostic and diagnostic scales to classify patients with severe sepsis or septic shock, which assess the degree of physiological affection and whose synergism improves the detection of hemodynamic alterations presented by patients. However, the amount of data to be analyzed (such as the isolated taking of vital signs, the invasive monitoring of central venous pressure, isolated blood pressure, and blood gases determination, among others) present disadvantages. Some of these are the result's safety, time employed, resources, and costs necessary for its implementation, which significantly complicate the assessment of these determinations for their use in clinical practice ${ }^{8}$.

In several studies, it has been observed that the shock index (SI), defined as the quotient between HR and systolic blood pressure (SBP), can predict early cellular hypoxia and hemodynamic compromise ${ }^{9-11}$.
Therefore, its use as a sepsis early detection marker has been supported: patients with a $\mathrm{SI}>0.7$ showed 3 times more hyperlactatemia than those with a $\mathrm{SI}<0.7^{12}$.

The association of the SI as an early indicator of sepsis in the pediatric population has been analyzed. However, previous studies did not determine the different cutoff points for age group, which are not the same in the whole pediatric population due to physiological conditions. Therefore, we decided to carry out this study with the objective of identifying the best time for the SI determination in the pediatric population to predict mortality in severe sepsis or septic shock.

\section{Methods}

A retrospective cohort from January 2012 to April 2014 was conducted, which included patients between 1 month and 16 years 9 months of age who developed severe sepsis or septic shock during their stay in the PICU. Patients who died during the first $6 \mathrm{~h}$ after their admission into the PICU were excluded from the study. The zero time was defined as the moment when the patient was admitted to the PICU with suspected sepsis. According to the assessment made by the attending physician and the researchers regarding the patient's clinical and laboratory data, the subjects were classified according to the criteria established by the International Pediatric Sepsis Consensus Conference 2005 as severe sepsis or septic shock. ${ }^{6}$

From the nursing records, the values of HR and SBP were identified at the time of diagnosis of severe sepsis or septic shock, and at 2, 4, and $6 \mathrm{~h}$ later. The quotient between HR and SBP was calculated to obtain the SI value corresponding to each moment.

By measuring the HR and SBP from the first suspicion of sepsis or septic shock diagnosis and consecutively every $2 \mathrm{~h}$ during the first $6 \mathrm{~h}$, the SI was determined for every subject at each time of measurement to 
construct four analysis times ( $\mathrm{SI}$ at diagnosis and at 2, 4, and $6 \mathrm{~h}$ later: SIO, SI2, SI4, and SI6). Subsequently, a comparison was made between two groups according to the outcome of the patients (survivors vs. deceased).

In both groups, variables that could modify the outcome were analyzed, such as age, sex, immunocompromise, heart problems, and days of hospital stay; and in the PICU stay, use of dobutamine, adrenaline, noradrenaline, levosimendan, and hydrocortisone or variables that could modify the SI, such as cardiovascular problems and age.

Hematooncologic patients who had received chemotherapy or patients with other conditions in which high doses of steroids that would cause immunosuppression were used, were considered immunocompromised. Patients who had a congenital or acquired heart disease were defined as having a heart problem. Before the start of the study, the protocol was approved by the institutional ethics committee: Comité de Investigación y Ética en Salud del Hospital de Pediatría Dr. Silvestre Frenk Freund.

\section{Statistical analysis}

Measures of central tendency and dispersion were used according to the measuring scale of the variables. The Shapiro-Wilk test was applied to determine the normal distribution of the quantitative variables.

The Mann-Whitney U-test was applied to compare the quantitative variables between groups and the $\chi^{2}$ test for qualitative variables. The risk factors were compared between the surviving and deceased patients, calculating the odds ratio (OR) and their confidence intervals (Cl). Two multiple logistic regression models were constructed for the SI4 and SI6. In these two models, the variables that in the bivariate analysis showed $p<0.1$ value were also included in the study.

All the statistical analyses were performed with SPSS software version 17.0 (IBM).

\section{Results}

The study included 165 patients who were admitted to the PICU during the established period. There was no sex predominance concerning the age group, and the most frequent one was that of the infants $(46.1 \%, n=76)$. The most frequent base diseases were oncological, cardiovascular, and gastrointestinal (56.4\%, $n=93)$ and only $7.3 \%(n=12)$ were previously healthy patients. Community-acquired pneumonia and
Table 1. Characteristics of the infection and microorganism isolation in patients included in the study.

\begin{tabular}{|l|c|}
\hline Characteristics & $\mathbf{n}(\%)$ \\
\hline Sex & \\
\hline Male & $82(49.7)$ \\
\hline Female & $83(50.3)$ \\
\hline Age group & \\
\hline Infant & $76(46.1)$ \\
\hline Preschooler & $27(16.4)$ \\
\hline School age & $37(22.4)$ \\
\hline Adolescent & $25(15.2)$ \\
\hline Base disease & \\
\hline Oncologic & $33(20)$ \\
Cardiovascular & $30(18.2)$ \\
Gastrointestinal & $30(18.2)$ \\
\hline Neurologic & $25(15.2)$ \\
Hematologic & $12(7.3)$ \\
Previously healthy & $12(7.3)$ \\
Genetic disorders & $8(4.8)$ \\
Immunological & $8(4.8)$ \\
Respiratory & $3(1.8)$ \\
Endocrine & $2(1.2)$ \\
Kidney diseases & $2(1.2)$ \\
\hline Reason for admission to the PICU & $37(22.4)$ \\
Community-acquired pneumonia & $32(19.4)$ \\
Oncological complications & $21(12.7)$ \\
\hline Seizures/status epilepticus & $13(7.9)$ \\
Post-myocardial infarction state & $11(6.7)$ \\
\hline Abdominal sepsis & $10(6.1)$ \\
Hospital-acquired pneumonia & $41(24.8)$ \\
\hline Others* &
\end{tabular}

*0thers: heart failure $(6,3.6 \%)$; neuroinfection $(4,2.4 \%)$; intracranial hemorrhage $(4,2.4 \%)$; sepsis $(3,1.8 \%)$; poliradiculoneuropathies $(3,1.8 \%)$; pleural effusion $(3,1.8 \%)$; digestive tract bleeding $(3,1.8 \%)$; hepatic encephalopathy $(3,1.8 \%)$; sever bronchospasm $(2,1.2 \%)$; acute pulmonary edema $(2,1.2 \%)$; hypoxic crisis $(2,1.2 \%)$; atrioventricular block $(1,0.6 \%)$; hypovolemic shock $(1,0.6 \%)$; surgical infection $(1,0.6 \%)$; diabetic ketoacidosis $(1,0.6 \%)$; bacterial tracheitis $(1,0.6 \%)$; infectious gastroenteritis $(1,0.6 \%)$. PICU: Pediatric Intensive Care Unit.

oncological complications were the most frequent pathologies that conditioned the admission to the PICU in $41.8 \%(n=69)$ (Table 1).

Of the 165 included patients, 137 (83\%) met septic shock criteria; the rest had severe sepsis. The sepsis origin was identified in a pulmonary focus in $49.6 \%$ of patients; in less than half of the cases, some microorganism was isolated through blood cultures, central venous catheter culture, bronchial secretion, or urine cultures. The microorganism that was most frequently isolated was Klebsiella pneumoniae in $5.5 \%$ of the patients (Table 2). There were 69 deaths (41.8\%) attributed to septic shock.

When comparing some characteristics between surviving and deceased patients, statistical differences were observed in the use of adrenaline, levosimendan, and hydrocortisone and the presence of septic shock. 
Table 2. Characteristics of the infection and microorganism isolation in patients included in the study.

\begin{tabular}{|l|c|}
\hline Characteristics & $\mathbf{n}(\%)$ \\
\hline Sepsis severity & \\
Septic shock & $137(83)$ \\
Severe sepsis & $28(17)$ \\
\hline Infectious foci & $122(73)$ \\
\hline Hospital-acquired pneumonia & $33(20)$ \\
Ventilator-associated pneumonia & $28(16.9)$ \\
Community-acquired pneumonia & $21(12.7)$ \\
Bacteremia & $14(8.5)$ \\
Abdominal sepsis & $13(7.8)$ \\
Associated with central venous catheter & $10(6.1)$ \\
Neuroinfection & $2(1.2)$ \\
Perinephric abscess & $1(0.6)$ \\
\hline Developing positive cultures & $42(25.4)$ \\
Peripheral blood culture & $23(13.9)$ \\
Central venous catheter culture & $10(6.0)$ \\
Bronchial secretion culture & $8(4.8)$ \\
Urine culture & $1(0.6)$ \\
\hline Isolation and microbiological identification & $42(25.4)$ \\
\hline Klebsiella pneumoniae & $9(5.5)$ \\
Pseudomonas aeruginosa & $8(4.8)$ \\
Escherichia coli & $7(4.2)$ \\
Enterobacter cloacae & $5(3.0)$ \\
Staphylococcus aureus & $4(2.4)$ \\
Others* & $9(5.5)$ \\
\hline
\end{tabular}

*Isolation and microbiological identification: Streptococcus pneumoniae $(2,1.2 \%)$; Acinetobacter baumannii (2, 1.2\%); Staphylococcus epidermidis $(1,0.6 \%)$; Burkholderia cepacia $(1,0.6 \%)$; Enterococcus faecalis $(1,0.6 \%)$; Candida parapsilosis $(1,0.6 \%)$; Candida famata $(1,0.6 \%)$.

Of the surviving patients, $70.8 \%$ presented septic shock while in the deceased patients $100 \%$ presented it (Table 3).

When performing the analysis according to the patient's condition, the median value in the severe sepsis group at SI0, SI2, SI4, and SI6 moments was 2.1, 2.0, 1.6 , and 1.4, respectively. While in the septic shock group, at SI0, SI2, SI4, and SI6, the median was 2.0, $2.0,1.9$, and 1.7 , respectively.

When analyzing the SI behavior between the patients who survived and those who died, it was determined that the median values at $\mathrm{SI} 0, \mathrm{SI} 2, \mathrm{SI}$, and $\mathrm{SI} 6$ were $2.0,2.0,1.6$, and 1.3 in the group of survivors, whereas the values were 2.0, 2.1, 2.2, and 2.4 for those who died. As observed in table 3 , the SIO median value was similar between the two groups $(p=0.642)$. However, in SI2, SI4, and SI6, it can be observed that the value tended to decrease in the survivors, while in the patients who died the value increased, which was statistically significant $(\mathrm{SI} 2 p=0.045$, SI $p=0.000$, and SI6 $p=0.000$ ) (Table 3). Particularly, of the 38 patients who had an $\mathrm{SI} \geq 2.2$ at $4 \mathrm{~h}$ of follow-up, only four survived, while of the 37 patients who had an $\mathrm{SI} \geq 2.4$ at $6 \mathrm{~h}$ of follow-up, none survived.

The OR of the SI values was calculated at each time to predict the outcome (death). For SI0 and SI2, no statistical significance was found (SI0: OR: 0.7; 95\% Cl: $0.32-1.5 ; p=0.42$ and SI2: OR: $2.16 ; 95 \%$ Cl: $0.9-$ 4.8; $p=0.6$ ), whereas for SI4 and SI6, a statistical significance was found (SI4: OR: 18.9; 95\% Cl: 7.249.6; $p<0.001$ and SI6: OR: 72.6; 95\% Cl: 21.3-246.9, $p<0.001$ ).

In the multiple logistic regression models, in addition to SI4 and SI6, the following variables were included sex, age (months), immunocompromise, cardiac problems, days of hospital stay, and PICU stay, as well as the use of vasoactive agents. In the first model performed for SI4, we observed a positive association between the SI (OR: 442.1; $p<0.001)$ and the death of the patient in an independent manner. In the same model, it was observed that in an independent manner, age (OR: 1.02; $p=0001$ ), adrenaline (OR: 17.1; $p=0.015$ ), and noradrenaline use (OR: $24.1 ; p=0.007$ ) increased the patients risk of death risk. In the second model performed for SI6, it was observed that the SI increased the death risk considerably, with an $\mathrm{OR}=81951.3(p<0.001)$. Age also increased the death risk (OR: 1.04; $p<0.001$ ) (Table 4).

\section{Discussion}

Despite the important advances in the pediatric sepsis management, there is still high morbidity and mortality secondary to severe sepsis and septic shock. For this reason, it is necessary to have clinical tools that help early detection of these conditions to implement therapeutic actions that modify their prognosis. Given the simplicity of its determination, the SI can be used in the emergency room where the taking of vital signs is a routine procedure, but not the measuring of other early markers of infection ${ }^{13,14}$.

This study showed that the increase in the SI value is directly associated with a higher mortality and that a high SI at 4 and $6 \mathrm{~h}$ after the severe sepsis or septic shock diagnosis predicts a patient's fatal outcome; particularly, the SI6 value predicts the patient's death (100\% of the subjects with SI6 $\geq 2.4$ died).

In children, normal SI values and their potential role in diagnosing severe sepsis or septic shock have not been well studied. However, some studies have performed SI measurements at $0,1,2,4$, and $6 \mathrm{~h}$ after admission and 
Table 3. Comparison of characteristics between surviving and deceased patients.

\begin{tabular}{|c|c|c|c|}
\hline \multirow[t]{3}{*}{ Characteristics } & Surviving & Deceased & \multirow[t]{3}{*}{$\mathbf{p}$} \\
\hline & $\mathrm{n}=96$ & $n=69$ & \\
\hline & \multicolumn{2}{|c|}{ n (\%) } & \\
\hline Males & $48(50)$ & $34(49.2)$ & NS \\
\hline Age (months) & $31.5(1-199)$ & $29(1-199)$ & NS \\
\hline Immunocompromised & $31(32.2)$ & $25(36.2)$ & NS \\
\hline Heart problem & $18(18.75)$ & $9(13.04)$ & NS \\
\hline Days of hospital stay & $8.5(0-124)$ & $11(1-94)$ & NS \\
\hline Days of PICU stay & $5(1-60)$ & $5(1-94)$ & NS \\
\hline Severe sepsis & $28(29.1)$ & - & 0.000 \\
\hline Septic shock & $68(70.8)$ & $69(100)$ & \\
\hline $\begin{array}{l}\text { Use of } \\
\text { Dobutamine } \\
\text { Adrenaline } \\
\text { Noradrenaline } \\
\text { Levosimendan } \\
\text { Hydrocortisone }\end{array}$ & $\begin{array}{c}36(37.5) \\
34(35.4) \\
29(30.2) \\
5(5.2) \\
3(3.1)\end{array}$ & $\begin{array}{l}35(50.7) \\
44(63.7) \\
27(39.1) \\
12(17.3) \\
11(15.9)\end{array}$ & $\begin{array}{c}\text { NS } \\
0.000 \\
\text { NS } \\
0.01 \\
0.004\end{array}$ \\
\hline $\begin{array}{l}\text { SI } \\
0 \\
2 \\
4 \\
6\end{array}$ & $\begin{array}{c}2(1.1-2.6) \\
2(0.9-2.6) \\
1.6(0.9-2.5) \\
1.3(0.5-2.3)\end{array}$ & $\begin{array}{c}2(0.9-2.8) \\
2.1(1.1-3.2) \\
2.2(0.9-3.2) \\
2.4(0.8-3.2)\end{array}$ & $\begin{array}{l}\text { NS } \\
0.04 \\
0.000 \\
0.000\end{array}$ \\
\hline
\end{tabular}

NS: non-significant; PICU: pediatric intensive care unit; SI: shock index.

showed that if at $6 \mathrm{~h}$ the SI value decreased it was not associated with mortality, but if it remained high, it was correlated with an increase in mortality ( $p=0.02$ vs. 0.03 ). These data go along with the literature. Among the most significant studies, we found that of Berger et al., a retrospective study with a population of 146 patients, in which it was demonstrated that the SI was predictive of the risk of death at 0,4 , and $6 \mathrm{~h}$ after severe sepsis and septic shock diagnosis and that children with an abnormal age-adjusted $\mathrm{SI}$ value at 0 and $6 \mathrm{~h}$ after diagnosis had a higher relative risk of death than children with normal age-adjusted SI value at 0 and $6 \mathrm{~h}$ after diagnosis. In this study, a correlation was also made with lactate, a widely used marker of severe sepsis. It was shown that the SI is a better marker than the HR or the SBP separately. This study did not divide the patients by age group, and the authors lost the initial correlation with lactate, which could have given them more information ${ }^{15}$.

Yasaka et al. performed a retrospective study and observed that the SI value at admission and up to $6 \mathrm{~h}$ after diagnosis was associated with mortality at the arrival into the PICU. When performing the stratification, they observed that the SI value was only associated with mortality in children aged 1-3 years and $\geq 12$ years $^{16}$. In certain groups, the SI value improvement at the PICU compared to the one presented at the admission moment was associated with an improvement in the patient's evolution concerning children with a higher SI value on admission. These observations demonstrated that the SI value determination within the first $6 \mathrm{~h}$ of admission into the PICU is an additional tool to assess the response to the initial resuscitation therapy.

On the other hand, it is necessary to clarify that the result of the multivariate analysis concerning the increased risk of death produced by the use of adrenaline and levosimendan was studied because it has been observed that, in the subjects that require the use of these drugs, generally severe hemodynamic changes persist ${ }^{17}$.

The results of the current study go along with the data reported in the literature ${ }^{16-19}$. The limitations of the study were the size of the sample, which was small in comparison with other studies; the collection of data as a 
Table 4. Multiple logistic regression model to calculate the risk of death correlated to the SI values at 4 and $6 \mathrm{~h}$ of follow-up in pediatric patients with severe sepsis and septic shock.

\begin{tabular}{|c|c|c|c|}
\hline Analyzed characteristics & OR & $95 \%$ CI & $\mathbf{p}$ \\
\hline Shock index (at 4 h) & 442.1 & $54.2-3601.7$ & $<0.001$ \\
\hline Sex & 0.59 & $0.21-1.61$ & NS \\
\hline Age (months) & 1.02 & $1.009-1.03$ & 0.001 \\
\hline Immunocompromised & 2.6 & $0.7-9.6$ & NS \\
\hline Heart problem & 0.41 & $0.1-1.7$ & NS \\
\hline Days of hospital stay & 0.97 & $0.9-1.02$ & NS \\
\hline Days of PICU stay & 1.08 & $0.9-1.1$ & NS \\
\hline $\begin{array}{l}\text { Use of } \\
\text { Dobutamine } \\
\text { Adrenaline } \\
\text { Noradrenaline } \\
\text { Levosimendan } \\
\text { Hydrocortisone }\end{array}$ & $\begin{array}{c}0.78 \\
17.1 \\
24.1 \\
1.6 \\
1.3\end{array}$ & $\begin{array}{c}0.2-2.2 \\
1.7-168.9 \\
2.4-239.2 \\
0.2-9.7 \\
0.2-9.3\end{array}$ & $\begin{array}{c}\text { NS } \\
0.015 \\
0.007 \\
\text { NS } \\
\text { NS }\end{array}$ \\
\hline Shock index (at 6 h) & 81951.3 & $427.1-15,700,000$ & $<0.001$ \\
\hline Sex & 0.1 & $0.02-1.4$ & NS \\
\hline Age (months) & 1.04 & $1.02-1.07$ & $<0.001$ \\
\hline Immunocompromised & 5.01 & $0.3-82.0$ & NS \\
\hline Heart problem & 0.3 & $0.02-3.6$ & NS \\
\hline Days of hospital stay & 0.9 & $0.7-1.1$ & NS \\
\hline Days of PICU stay & 1.2 & $0.9-1.6$ & NS \\
\hline $\begin{array}{l}\text { Use of } \\
\text { Dobutamine } \\
\text { Adrenaline } \\
\text { Noradrenaline } \\
\text { Levosimendan } \\
\text { Hydrocortisone }\end{array}$ & $\begin{array}{c}0.3 \\
46.2 \\
61.8 \\
0.17 \\
0.2\end{array}$ & $\begin{array}{c}0.03-3.6 \\
0.2-10110 \\
0.2-15625 \\
0.008-3.5 \\
0.01-6.0\end{array}$ & $\begin{array}{l}\text { NS } \\
\text { NS } \\
\text { NS } \\
\text { NS } \\
\text { NS }\end{array}$ \\
\hline
\end{tabular}

OR: odds ratio; Cl: confidence interval; PICU: pediatric intensive care unit; SI: shock index.

retrospective study, it is limited to the information documented in the clinical records, and in some cases, it is insufficient. For this reason, it is considered convenient in the future to carry out a prospective study that will allow the researchers to obtain more reliable information to be analyzed.

It can be concluded that, in general, the best time to predict mortality through the SI value is $6 \mathrm{~h}$ after initiated resuscitation of pediatric patients with severe sepsis or septic shock, with an OR of $81951.3 ; 95 \% \mathrm{Cl}$ : 427.1$15,700,000$. The diffusion of the usefulness of SI value in pediatric patients, especially in the first contact services, as well as its determination, can be valuable to modify the clinical evolution of a patient with sepsis or septic shock within the first $6 \mathrm{~h}$ of admission into the PICU.

\section{Ethical disclosures}

Protection of human and animal subjects. The authors state that the procedures followed were conformed to the ethical standards of the committee on responsible human experimentation and in accordance with the World Medical Association and the Declaration of Helsinki.

Confidentiality of data. The authors declare that they have followed the protocols of their work center on the publication of patient data.

Right to privacy and informed consent. The authors have obtained the written informed consent of the patients or subjects mentioned in the article. The corresponding author is in possession of this document. 


\section{Conflicts of interest}

The authors declare no conflicts of interest.

\section{References}

1. Bryce J, Boschi Pinto C, Shibuya K, Black RE. WHO estimates of the causes of death in children. Lancet. 2005;365:1147-52.

2. Dellinger RP, Carlet JM, Masur H, Gerlach H, Calandra T, Cohen J, et al Surviving Sepsis Campaign guidelines for management of severe sepsis and septic shock. Crit Care Med. 2004;32:858-73.

3. Hartman ME, Linde-Zwirble WT, Angus DC, Watson RS. Trends in the epidemiology of pediatric severe sepsis. Pediatr Crit Care Med. 2013, 14: $686-93$.

4. Weiss SL, Fitzgerald JC, Pappachan J, Wheeler D, JaramilloBustamante JC, Salloo A, et al. Sepsis Prevalence, Outcomes, and Therapies (SPROUT) Study Investigators and Pediatric Acute Lung Injury and Sepsis Investigators (PALISI) Network. Global epidemiology of pediatric severe sepsis: the sepsis prevalence, outcomes, and therapies study. Am J Respir Crit Care Med. 2015;191:1147-57

5. Stevenson EK, Rubenstein AR, Radin GT, Wiener RS, Walkey AJ. Two decades of mortality trends among patients with severe sepsis: a comparative meta-analysis. Crit Care Med. 2014;42:625-31.

6. Goldstein B, Giroir B, Randolph A, and the members of the International Consensus Conference on Pediatrics Sepsis. International pediatric sepsis consensus conference: Definitions for sepsis and organ dysfunction in pediatrics. Pediatr Crit Care Med. 2005;6:2-7.

7. Pacheco-Rosas DO, Huelgas-Plaza AC, Miranda-Novales MG. Serum lactate as a biomarker of severe sepsis in children with cancer, neutropenia and fever. Rev Med Inst Mex Seguro Soc. 2014;52:S24-9.

8. Alkhouli M, Solaiman AY, Zhao H, Morad A, Escarcega RO, O'Murchu B, et al. Clinical utility of central venous saturation for the calculation of cardiac index in cardiac patients. J Card Fail. 2014;20:716-22.
9. Zhang X, Wang Z, Wang Z, Fang M, Shu Z. The prognostic value of shock index for the outcomes of acute myocardial infarction patients: A systematic review and meta-analysis. Medicine (Baltimore). 2017; 96:e8014.

10. Kobayashi A, Misumida N, Luger D, Kanei Y Shock Index as a predicto for in-hospital mortality in patients with non-ST-segment elevation myocardial infarction. Cardiovasc Revasc Med. 2016;17:225-8.

11. Strehlow MC. Early identification of shock in critically ill patients. Emerg Med Clin North Am. 2010;28:57-66.

12. Rousseaux J. Prognostic value of shock index in children with septic shock. Pediatr Emerg Care. 2013;29:1055-9.

13. Torabi M, Moeinaddini S, Mirafzal A, Rastegari A, Sadeghkhani N. Shock index, modified shock index, and age shock index for prediction of mortality in Emergency Severity Index level 3. Am J Emerg Med. 2016;34:2079-83

14. Ray S, Cvetkovic M, Brierley J, Lutman DH, Pathan N, Ramnarayan P, et al. Shock index values and trends in pediatric sepsis: Predictors or therapeutic targets? A retrospective observational study. Shock. 2016;46: 279-86.

15. Berger T, Green J, Horeczko T, Hagar Y, Garg N, Suarez A, et al. Shock index and early recognition of sepsis in the Emergency Department: pilot study. West J Emerg Med. 2013;14:168-74.

16. Yasaka Y, Khemani RG, Markovitz BP. Is shock index associated with outcome in children with sepsis/septic shock? Pediatr Crit Care Med. 2013;14:e372-9.

17. Belletti A, Benedetto U, Biondi-Zoccai G, Leggieri C, Silvani P, Angelini GD, et al. The effect of vasoactive drugs on mortality in patients with severe sepsis and septic shock. A network meta-analysis of randomized trials. J Crit Care. 2017;37:91-8.

18. Rappaport LD, Deakyne S, Carcillo JA, McFann K, Sills MR. Age and sex specific normal values for shock index in National Health and Nutrition Examination Survey 1999-2008 for ages 8 years and older. Am J Emerg Med. 2013;31:838-42.

19. Yussof SJ, Zakria MI, Mohamed FL, Bujang MA. Value of shock index in prognosticating the short-term outcome of death for patients presenting with severe sepsis and septic shock in the emergency department. Med J Malasia. 2012;67:406-11. 